\title{
REVOLUTIONALIZING AGRICULTURE EXTENSION DELIVERY THROUGH MOBILE TELEPHONY: THE EXPERIENCE OF VILLAGE ENTERPRISE AGENT MODEL IN GREATER MASAKA AREA, UGANDA
}

\author{
NICHOLAS MUGABI ${ }^{1,2}$, ANDREW ELLIAS STATE ${ }^{1}$, JULIUS OMONA $^{1}$ \& BIRGITTA JANSSON ${ }^{2}$ \\ ${ }^{1}$ Makerere University, Uganda \\ ${ }^{2}$ University of Gothenburg, Sweden
}

\begin{abstract}
Agriculture continues to be the thrust of Uganda's economy, directly employing majority of the population. However, there is deficiency in extension service delivery with few trained extension workers to support smallholder farmers. As a result, there have been strides to revolutionize traditional agriculture extension delivery through Village Enterprise Agent Model using mobile telephony digital extension platform. A cross sectional study design was adopted using ethnographic interviews and survey questionnaire with 70 VEAs. The diffusion of innovation theory and technology acceptance model are applied to examine the VEAs' experience in using mobile telephony as a tool to deliver agriculture extension services. Explicitly, the study investigated the capacity of VEAs to deliver extension services, how they do it, the kind of information delivered and the challenges to this model. Study findings revealed that social networks of farmer groups are key diffusion channels through which VEAs reach smallholder farmers. Adopters' characteristics such as VEAs' education background, community leadership skills and prior experience in using mobile telephony has a strong bearing on the ease of disseminating digital messages to farmers. In addition, the Kulima mobile telephony digital platform has supported real time dissemination of agricultural information. This is integrated with pragmatic demonstration gardens, farmer exchange visits, home visits to enhance farmers' peer learning. The sustainability of VEA model, with no clear incentive system, amidst complicated agriculture terminologies used in digital messages are some of the challenges to the model. Thus, future extension delivery using community agents and information communication technology should be cognizant of the social cultural dynamics, social nodes and ties of farmers and translate mobile digital messages into indigenous languages.
\end{abstract}

Key words: agriculture extension, village enterprise agents, mobile telephony, digital messages and smallholder farmers

\section{INTRODUCTION}

\subsection{Background}

The twenty first century has witnessed the influx of massive technological innovations and inventions with several technology platforms and tools ranging from mobile telephony, computers, laptops, tablets, satellites, television, radio, videos and social media platforms. Mobile telephony as a tool to deliver agricultural extension services is one of the information communication technologies (ICTs) tools [1] implemented in Uganda. Changing the way farmers communicate and exchange information with extension workers, researcher and agricultural scientists. ICTs are a great opportunity in the context of high literacy of African farmers with limited access to extension services [2]. Likewise, in their study [3] argued that since few farmers are blessed with regular visit of an extension agent, deployment of video and mobile telephone technologies would bridge this information gap. 
In this case, mobile telephony is not a mere communication tool but it is also used to disseminate agriculture information including agronomy, weather, market information and financial services information [4]-[7]. The innovative use of mobile telephony to disseminate information to smallholder farmers is because of the deficits in traditional extension service delivery with high extension workers to farmer ratio. For example, in Uganda extension officer to farmers is 1:2,500 against the United nations Food and Agriculture Organization (FAO) recommended ratio of 1:400 [8]. Yet a large portion (73\% women and $75 \%$ men) of Uganda's smallholder farmers still live in rural areas [9]. Smallholder farmers are thus defined as those with an average farm size of between 0.8 and 1.7 hectares, live below the poverty line of US\$2.50 a day with large households, dependent on family labour and more labour intensive farming, no value addition for their produce, have limited land rights, limited access to competitive market with better prices and have limited access to improved agroinputs, yet with little yields from crop and livestock production [4], [10]-[14]. To address the predicament of smallholders, there have been strides to revolutionize agriculture extension delivery using digital platform customized on community Volunteers' mobile phone.

The Grameen Foundation Uganda was the first to develop and deploy an SMS-based comprehensive system to help deliver market information to farmers in Uganda; with the Village Phone network via such programs as Application Laboratory since 2008. In partnership with Mobile Telephone Network (MTN) Uganda, a private telecommunication company and Google, Grameen leveraged the MTN's network of village phones with 35,000 public phone operators to test and deliver mobile information services to rural communities [5], [15]. Grameen Foundation also identified, recruited and trained a network of Community Knowledge Workers (CKWs) as mobile telephony extension agents within their communities. CKWs (not professionally trained extension workers) support their peers with agricultural extensions services using smartphones preloaded with agriculture information. Building on the CKW program [4]-[7], Lutheran World Relief [16] and her partners Community Enterprises Development Network (CEDO) and Gutsinda Development Group under flagship of Sustainable Enterprises for Trade Engagement (SENTE) Project, rolled out a mobile telephony agricultural extension platform called Kulima [6]. In turn, farmers are expected to apply this knowledge in their farming practices so as to improve on farm production and productivity.

The VEA model is intended to transform the agricultural sector across the value chain; from farmer level to marketing and value addition. Through VEAs farmers have access to real time information: agronomic practices, weather, fertilizer application post-harvest handling, storage, value addition and marketing opportunities [1], [4], [7], [8], [17]-[19]. Mobile telephony is used to convey quality and reliable agricultural information, while farmers also enquire about new agricultural practices, crop varieties and diseases [20].

The purpose of this article is to examine the VEAs experience in using mobile telephony among other ICTs to deliver agriculture extension services to smallholder farmers in greater Masaka area of Uganda. The key research questions included: What are the capacities of VEAs to deliver extension services? How is the VEA model implemented? What are the challenges to this model?

\section{THEORETICAL FRAMEWORK}

The study is conceptualized within the Technology Acceptance Model [21] and the Diffusion of Innovation Theory (DIT). The TAM presents the end-users' attitudes on the usage of technology; either to resist or accept the technology [19], [22]-[24]. Two premises of TAM; the perceived usefulness and perceived ease of use are examined as proposed by [2], [25]. In this case, perceived usefulness refers to the prospective end user's subjective probability that 
mobile technology will increase job performance (extension delivery and farmers' productivity). On the other hand, ease of use is the degree to which the prospective end user expects the technology to be free from over excessive effort during application; ease of use of telephony mobile extension platform [22], [24], [25]. It should however be noted that ease of use and usefulness of ICTs varies from one tool and users' need to another.

In addition, the study examines the DIT; diffusion here refers to the process of communicating the innovation among the members of social system [26]-[28]. DIT is based on three parameters of innovation decision process, communication channels and characteristics of adopters [27]-[30]. Innovative decision process is concerned with VEA and smallholder farmers' awareness, interest, evaluation, trial and adoption of the mobile telephony extension. Communication channel on the other hand refers to the conduits through which technology is delivered for example through mass media and interpersonal relations/resources. Characteristics of the adopter have to do with traits of mobile telephony extension end users: their socio-economic status, mass media exposure and extension services [26], [28]-[31]. Specifically, this study adopted the last two aspects of DIT namely; communication channels and characteristics of adopters which influence VEAs and farmers' access and use of mobile telephony extension tool.

\section{RESEARCH METHODS}

This study adopted a cross sectional study design, using ethnographic in-depth interviews with five VEAs, three focus group and survey questionnaire with 70 VEAs. The study was conducted in 2017 in greater Masaka area, Uganda. Specifically, VEAs are in the districts of Masaka, Rakai (includes the new district of Kyotera district), Sembabule, Kalungu, Lwengo, Lyantonde and Bukomansimbi. The study area was purposively selected due to the fact that mobile telephony agriculture extension delivery has been implemented in the area since 2014 . Participants were drawn purposively from a network of 70 VEAs who are also beneficiaries of the Sustainable Enterprises for Trade Engagement (SENTE Project). The survey questionnaire was administered to 70 purposively sampled VEAs, while the subsequent interviews and focus groups were carried with VEA within greater Masaka area. In terms of data analysis, survey questionnaire data was collected using mobile phones digital platformOpen Data Kit (ODK) technology relayed on saleforce.com web-based platform. The data was directly uploaded to the Salesforce.com system using the Smartphones at the end of every survey interview. The uploaded data entries were then exported into Microsoft Excel as CSV file and transferred to SPSS Windows 24.0 computer software for statistical analysis. Focus group discussion and key informant interview notes were analyzed using content analysis with themes and sub-themes corresponding to the research questions.

Ethically, our study was reviewed and approved by the Makerere University School of Social Sciences Research Ethics Committee (MAKSSREC 12.17.108), and the Uganda National Council for Science and Technology (SS 4591). All participants affirmatively consented to participate in the study, and where secondary data was used due acknowledgement is made. The study findings are presented and discussed below.

\section{RESULTS AND DISCUSSION}

\subsection{The capacity of Village Enterprise Agents (VEA) to deliver extension services}

The study sought to understand the capacity of VEAs to delivery extension services using mobile telephony digital platform. We found out that majority $(81 \%)$ of VEAs were male compared to $19 \%$ female. This gender disparity is in tandem with the world view that 
agriculture is a male dominated activity, and ownership and control of household assets such as mobile phone is mainly by man at least in Africa. This confirms the global gender mobile gap where women on average are $14 \%$ less likely to own a mobile telephony and use mobile telephony less frequently and intensely than men [32]. This is also embedded in patriarchal nature of Ugandan communities where males show up and want control when there are community initiatives that offer prospect for extra income and dominance.

The median age of VEAs was 36 years, with majority in the age bracket of 33-44 and 4556 years representing $36 \%$ and $31 \%$ respectively. Only $17 \%$ were in the age bracket of youth (21-32 year) and 13\% were 57 years and above. The age of VEA is not a surprise because during their recruitment, the focus was on people with experience in community work and command of respect to serve as community extension agents. Collaborative evidence from focus group discussions with VEA also alludes to this subjectivity as narrated by the respective male and female VEA in Masaka district of Uganda:

I was a leader in Balikyewunya Samad Group (poultry farmers). I was the chairperson: it was from there where I was selected in Kilumba parish by a local NGO-Community Enterprises Development Network (CEDO) to do work in it. I was the one selected by the members from the group to be their VEA (Male VEA).

Before I entered SENTE (Sustainable Enterprises for Trade Engagement) project I was a farmer growing mainly coffee and beans. I joined a savings group in my village, it is from this savings group that I was selected and given interviews that I passed and was selected to become A VEA (Female VEA).

However, literacy and cultural factors (social norms) such as patriarchal limit female participation in community development programs and women experiencing barriers to mobile telephony ownership and use [32], [33]. In this case we found that VEA selection and recruitment was subjective and not gender sensitive. Though it was also noted that identify female volunteers who own phones, with ability to read and write, and with commitment to serve their communities [34] challenging.

In terms of level of education, $57 \%$ of VEAs have Ordinary secondary level of education, $24 \%$ had tertiary certificates education, $10 \%$ with advance secondary level and $9 \%$ had primary level of education. The selection criterion of VEAs was based on their reading capabilities, ability to understand and interpret English at least at basic level. This was done through face to face interview that involved reading a portion of the mobile phone content in English and translating it in the local languages mostly Luganda and Runyankole [34]. The selection of the VEAs was also hinged on social networks of farmer groups. VEAs contested voluntarily and were selected by group members to serve them as extension agents. This has sameness to the traditional National Agriculture Advisory Services (NAADS) farmer field schools recruitment process; where participants with strong social connections or belonged to preexisting community groups [7], [35], [36] had chance to participate. NAADS based on farmer groups and farmer field schools aims at high level of farmer participation in technology generation and dissemination [7], [36]-[43]. Likewise, VEAs are from within their group membership without the interference of community leaders and politicians.

It should however be noted that upon recruitment, VEAs were empowered with specialized training for one week in effective use of the smart phones technology, e-tools, Kulima agricultural digital platform of extension and mobile data collection using ODK. This was attested to by VEAs who participated in the FGD, for example one male VEA narrated the process of recruitment and training as below: 
When I was selected to lead the farmer groups, there were leaders from a local NGO called Community Enterprise Development Network (CEDO); who came and interviewed me with other group members. They came with the phones, gave me the mobile telephony phones and I was asked to read what was on the phone screen. I was able to read it. Later I received a phone call informing me that I had passed the interview. I was told to go for training in Masaka on how to use a phone. The organisation which taught us for a week was called Gutsinda, they taught us how to operate a phone. After the training, they gave me and other successful VEAs.

In addition, VEAs were trained in financial literacy specifically the Village Savings and Loan Associations (VSLA) model, group dynamics and cooperative principles (bulking and collective marketing). This avows [44] argument that effective extension services delivery is highly dependent on the ability of extension workers who are competent; though job performance of extension agents is dependent on other competences as well.

\subsection{VEA's prior experience}

It was found out that prior $77 \%$ of VEAs were model smallholder farmers, $9 \%$ have experience in agriculture extension, $9 \%$ are trained teachers and $5 \%$ dealt in varied business enterprises within their community. VEA have social networks of farmer groups they support with an average ratio of 1:6 groups and an average farmer ratio of 1:300, slightly below FAO recommended ratio of 1:400 and much lower than general Uganda's extension officer to farmers ratio of $1: 2,500$ [8]. This ratio is very low and impressive which guarantee frequency and intense of VEA to farmer interaction and knowledge exchange. Uniquely, VEAs with prior experience in agriculture extension and strong ties with farmers were found to be more efficient and supportive to farmers compared to their counterpart, who find difficulty in providing extension services to farmers. Secondly, VEAs who had routine interactions with professional extension workers (with a ratio of 1:12 and at least on a monthly basis) found it easy to disseminate information to farmers.

Previous community leadership experience was found to be one of the capabilities of VEAs. For example, over $93 \%$ of VEAs were group leaders, model farmers serving in different group positions such as chairpersons, mobilizers and general Secretary. This facilitates easy mobile telephony extension delivery, since VEAs had community leadership, mobilization and group dynamics skills. In addition, all VEAs had prior knowledge and experience in using a mobile telephony especially feature phones. But very few had prior interface with android/smart phones. VEAs could ably make a phone call, save phone contacts, send, receive and read text message both in English and their local languages. Such VEA's competencies in using the mobile telephony, is also presented by [45] in their study of media information of Plantation Genetic Resources in West Papua as attitude tendencies of utilizing ICTs. In their study, this had a positive (82\%) moderate category and $18 \%$ high category with attitude tendencies utilizing laptops, smartphones for surfing among Cocoa farmers in South Manokwari Regency West Papua province of Indonesia [45]. Likewise, Cooper and Graham [46] in their study about competencies needed to be successful County Agents and County Supervisors in Arkansas, describes the above VEA attributes and experience as important competencies related to program planning, implementation, and evaluation, public relations, personal and professional development. Nonetheless, the competency description applies more to specialized extension workers who are at higher level than VEAs who are lay agents. 


\subsection{The kind of information delivered to smallholder farmers}

VEA Model clouts agricultural information in the hands of smallholder farmers through the Kulima Mobile Digital Content Platform to disseminate information and facilitate knowledge transfer. The platform integrates image and voice capture to assist in diagnosing problems and explaining practical good agriculture solution. The Kulima digital content is customized as an offline application, with varied agriculture information developed by agriculture scientists on wide spectrum of value chains. This was further explained by a male VEA who is also a trained extension assistant working as a private extension worker in the study area:

There is an application called KULIMA where we find information concerning agriculture for instance the growing of beans, knowing the different types of beans, the pests and diseases that attack the beans then I can go back to the farmer and see what is happening. It is put in English language that is easily understood, the information is sufficient enough. There is a lot of information in Kulima but Kulima needs to be updated always for instance the type of maize for example Longe 4 which is not on the phone.

The VEAs deliver agriculture extension information is in a style described by [45] as verbally, motion mimic, physical and written to change one's behavior both knowledge and skills. Borrowing from [44] the competencies influencing Extension Workers' job performance in relation to the good agricultural practices in Malaysia, the VEA model is embedded in the interdependence mode extension; effectiveness of extension services and extension workers' roles. However, the Kulima agriculture content is in English language with some complicated terminologies which cannot be easily translated by VEA, given the fact that majority only have Ordinary secondary level of education. Below figure 1 shows the layout of the VEA model Kulima Content Digital platform and VEA disseminating information to a farmer:

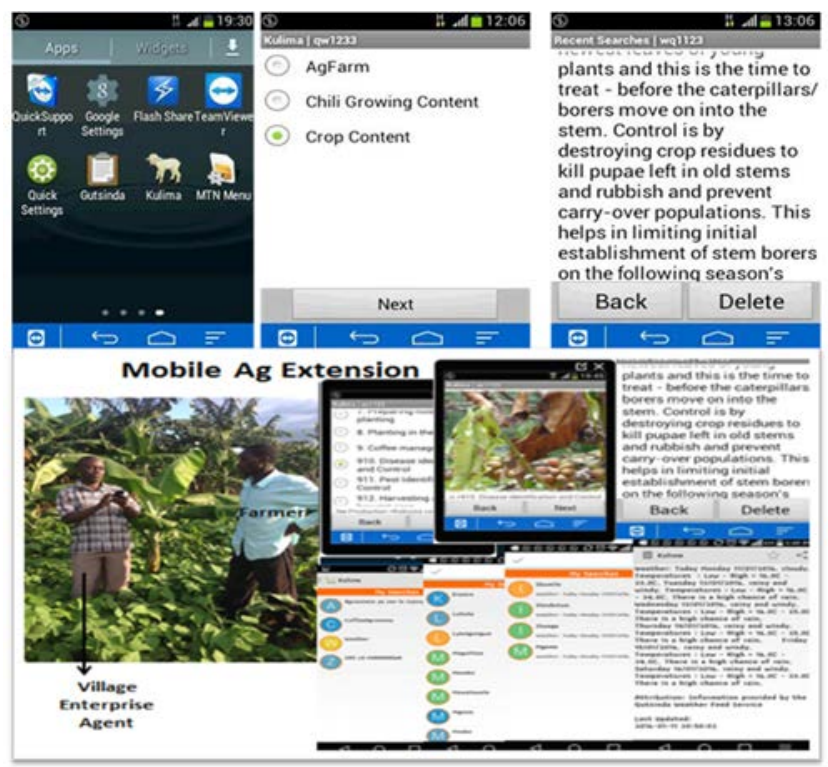

Figure 1: VEA Model Kulima Content Digital platform. (Sources: Adopted from Gutsinda [34].) 
The Kulima platform is however integrated with practical farmers' skill development simulations such as demonstration gardens, farmer exchange visits, home visits and peer learning during meetings. This is the broadened extension services as described by [33] which include community meetings and group meetings, which was also adopted in NAAD farmer field schools. Other studies have alluded that the above varying extension teaching methods enhance extension agents' competency [44]. We also observe that the VEA model confirms to what [46] described in their study as an extension method with social competency; ability to interact effectively with farmers, colleagues and supervisor.

The model provides information on agronomy, marketing, weather, harvest and postharvest handling for crops such as maize, coffee, banana, beans and tomatoes. This is also documented by [20] who argued that mobile telephony is used by extension workers to convey quality and reliable agricultural information, while farmers also enquire about new agricultural practices, crop varieties and diseases. The VEA model uses an offline Kulima application which can be accessed anytime by VEAs. This is not the case with other ICT tools for extension which are internet based, as the case is with Cyber Extension/ web [45]: a medium of information through computers and smartphones which is an information system using the internet media.

\subsection{Limitation of VEA model}

The VEA model is a novel extension approach compared to the traditional extension approaches, as it eased access to real time extension information. Nevertheless, the model has some limitations. These range from the structural prototype of the model, policy gaps and geographical scope. For instance, the Kulima content platform has limited agricultural information biased to the three value chains of maize, coffee and beans, yet smallholder farmers in Uganda practice mixed farming and intercropping. Thus, farmers require varied agricultural information at different times within the seasons. It was also noted, there is irregular update of the Kulima content. For example, one male VEA explained this further:

There is a lot of information in Kulima but Kulima needs to be updated always for instance about the varieties of maize, Longe 4 is missing on the phone yet it is on the market. Information on emerging pest and diseases for example the maize armyworm (Fall Armyworm) which has been attacking maize yet in the Kulima app it is not included therefore it needs to be updated.

The model only benefits SENTE project farmers, with exclusions of other farmers who not project beneficiaries. This is the same limitation with NAADS and CKW program in Uganda [4], [5], [7]. This creates two categories of farmers, one category for farmers who have access to VEA and those who do not. Not to negate the spill off effect of farmer to farmer knowledge sharing (including those who are not intended project beneficiaries), since the VEAs model was not a typical randomized controlled trial project with strict exclusivity to guard against diffusion of information to none VEA group members. Worse still, VEA model was a short term three years project, with limited geographical scope of only seven districts in greater Masaka area. The project only targeted 2\% (17,000 farmers) of the estimated 689,385 farmers within the study districts according to the recent 2014 population census [47].

Lastly, there are major gaps between policy and actual implementation of ICT driven extension approaches such as the VEA model. While the government of Uganda agitates for integration of ICT within extension deliver, it is not yet fully integrated in the government extension policy and strategy [37], [48]. It is debatable that VEA innovative model could 
suffer the same description by [33] as a kind of innovation which is superficial innovation. Such superficial innovations are supply driven and are far from transformative reality marred by various challenges as narrated preceding sections above.

\subsection{Discussion}

Social networks of farmer groups were found to be key diffusion channels of the VEA mobile telephony digital extension platform. Through farmer community group structures VEAs support smallholder farmers with extension services. These community structures increase VEA-farmers' interactions, knowledge sharing and peer to peer learning. Hence empowerment of smallholder farmers is embedded within their social structures.

The Kulima mobile telephony digital platform was found to be userfriendly and useful. It is useful in disseminating agriculture information to smallholder farmers even in rural areas with limited access to extension workers. Kulima platform increased job performance (extension delivery) because it does not require excessive effort to use. Thus, ease of adoption of agriculture extension knowledge content platform by VEAs. This mitigates the extension gap within the orthodox extension approach which is dependent on extension workers who are few, poorly facilitated and motivated. However, VEAs are not specialized ICT experts to manage complicated challenges with Kulima technology. As a result, the model overly depends on the technical support of an ICT officer whose designation is centralized at the project office. Many VEAs reported hardships in travelling to central office for technical support. Secondly technical issues such as phone breakdown, solar charge solutions and network failure are not handled by the ICT project expert and yet VEAs were not linked to any reliable support service provider, hence some VEAs were hampered by gadget failure.

The adopter characteristics such as education level, leadership experience and qualities, and spirit of voluntarism play a strategic role in VEAs ease to use mobile telephony extension platform and dissemination of agricultural extension services to farmers. Thee above VEA qualities are purposive and were the basis upon which VEAs were selected by their group members to serve them as a model farmer and VEA. The VEAs adopter characteristics were further strengthened by trainings, continuous mentor and support supervision by the field extension workers and Gutsinda technical team. The VEAs however became white elephants among smallholder farmers. Farmers are reliant on an individual VEA whose professional conduct, integrity, commitment, interpersonal relations and social network affect extension delivery. As a result, some farmers could not be reached by VEAs because VEAs had the autonomy to decide which farmers to reach out or not.

The VEAs rely on the Kulima infrastructure platform built as an application downloaded to the android phone overlaid with scientific content of agricultural information (in English language) on agronomy, market information, weather information, harvest and post-harvest handling information, and financial service information. The VEAs in turn read and translate the information to farmers in Luganda and Runyankole with some photos and videos on basic practical skills. The study however, revealed that the process of content development and update by Gutsinda Development Group need to be strengthened, with regular update of the content to cater for emerging farming challenges and farmers' farming needs. In addition, some VEAs have difficulty in translating scientific terminologies used in Kulima App and hampered by limited and inefficient backstop system of extension workers who are experts in agriculture extension. Worse still, the Kulima app agriculture extension tools are not yet adopted by the main stream Ministry of Agriculture Animal Industry and Fisheries (MAAIF), the mandated government agency to ensure equitable and sustainable agriculture extension 
delivery to smallholder farmers. As a result, there is limited government awareness and buyin on mobile telephony extension despite its advantages.

\section{CONCLUSION}

The study findings revealed that social networks of farmer groups are a key diffusion channel through which extension agents reach smallholder farmers with ease. Adopters' characteristics such as VEAs' education background, community leadership and prior experience with mobile telephony have a strong bearing on the ease of translating English mobile telephony digital messages to farmers. In addition, VEA find it easy and useful to use mobile telephony digital platforms to disseminate agriculture information leveraging local knowledge through peer to peer learning and support. The sustainability of community extension agent model introduced by a donor dependent NGO, with complicated agriculture terminologies used is critical challenge to the model. Thus, effective future extension delivery programming using community agents and ICTs should be cognizant of the social cultural dynamics, social nodes and ties of farmers. Translation of mobile telephony digital messages into indigenous languages is imperative for effective extension delivery and communication. The model can be effective with strengthened technical backstopping mechanisms of VEAs with specialized extension workers support supervision and mentorship. Lastly, there is need to review the current Uganda's Ministry of Agriculture Animal Industry and Fisheries extension policy and strategy 2016 to integrate mobile telephony tools in the delivery of extension services in Uganda to compliment the traditional extension approaches.

\section{ACKNOWLEDGEMENTS}

We acknowledge Makerere University specifically the Makerere-Sweden Bilateral Research Program (MAK-SIDA Program) 2015/2016 and The Integrating Gender and Nutrition within Agricultural Extension Services (INGENAES) Fellowship 201602017 for the financial support.

\section{REFERENCES}

[1] Munyua, H. \& Adera, E., Emerging ICTs and their potential in revitalzing small-scale agriculture. Agricultural information worldwide, 2(1), pp. 3-9, 2009.

[2] Sousa, F., Nicolay, G. \& Home, R., Information technologies as a tool for agricultural extension and farmer to-farmer exchange: Mobile-phone video use in Mali and Burkina Faso. International Journal of Education and Development using Information and Communication Technology, 12(3), pp. 19-36, 2016.

[3] Van Mele, P., Wanvoeke, J., Rodgers, J, \& McKay, B., 30 Innovative and Effective Ways to Enhance Rural Learning in Africa, CAB International Realizing Africa's Rice Promise. 2013:367-78.

[4] McCole, D., Culbertson, M.J., Suvedi, M. \& McNamara, P.E., Addressing the Challenges of Extension and Advisory Services in Uganda: The Grameen Foundation's Community Knowledge Worker Program. Journal of International Agricultural and Extension Education, 21(1), 2014.

[5] Gantt, W. \& Cantor, E., Direct Data on demand: Mobile Apps Deliver a Broad Range of Information to Ugandan Farmers. http://ictupdate.cta.int/en/FeatureArticles/Direct-data-on-demand, Washington: Grameen Foundation, 2010.

[6] Kimbowa, J., Mobile Advisory App Raises Hopes of Lwengo Farmers, Kampala: Observor Newspaper, 2015.

[7] Ninsiima, D., Factors Affecting Adoption of an Information Communications Technology System for Agriculture in Uganda, Michigan State University, 2015. 
[8] Ongachi, W., Onwonga, R., Nyanganga, H. \& Okry, F., Comparative analysis of video mediated learning and farmer field school approach on adoption of striga control technologies in Western Kenya. International Journal of Agricultural Extension, 5(1), pp. 1-10, 2017.

[9] UBOS, Uganda National Household Survey (UNHS), Kampala: Uganda Bureau of Statistics, 2017.

[10] Anderson, J., Learch, E.C. \& Gardner, T.S., National Survey and Segmentation of Smallholder Households in Uganda: Understanding Their Demand for Financial, Agricultural, and Digital Solutions, CGAP, 2016.

[11] Pauw, K. \& Thurlow, J., Prioritizing rural investments in africa: a hybrid evaluation approach applied to Uganda. The European Journal of Development Research, 27(3), pp. 407-424, 2015.

[12] Kraybill, D., \& Kidoido, M., Analysis of Relative Profitability of Key Ugandan Agricultural Enterprises by Agricultural Production Zone, International Food Policy Research Institute (IFPRI), 2009.

[13] MOFPED, Poverty Status Report 2014: Structural Change and Poverty Reduction in Uganda. Kampala: Ministry of Finance, Planning and Economic Development; 2014.

[14] UBOS, Uganda National Household Survey 2016/2017, Kampala: Uganda Bureau of Statistics (UBOS), 2017.

[15] Okyere, K.A. \& Mekonnen, D.A., The Importance of ICTs in the Provision of Information for Improving Agricultural Productivity and Rural Incomes in Africa, UNDP, editor. Working Paper. Regional Buruea for Africa, 2012.

[16] LWR. Information Communication Technology for Development, Baltimore: Lutheran World Relief, 2018.

[17] May, J., Karugia, J. \& Ndokweni, M., Information and Communication Technologies and Agricultural Development in Sub-Saharan Africa: Transformation and Employment Generation, AERC Final Framework Paper. Kwazulu-Natal, 2007.

[18] Aker, C.J., Dial A for agriculture: A review of information and communication technologies for agricultural extension in developing countries. Journal of Agricultural Economics, 42, pp. 631-647, 2011.

[19] Bell, M., Information and Communication Technologies for Agricultural Extension and Advisory Services: ICT-Powering Behavior Change for a Brighter Agricultural Future, United States Agency for International Development (USAID) project Modernizing Extension and Advisory Services (MEAS). MEAS Discussion Paper, 2015.

[20] Bukenya, G., The Mobile Phone: A Solution to Rural Agricultural Communication a Case Study of Rakai district, Uganda, The Technical Centre for Agricultural and Rural Cooperation (CTA), 2016.

[21] Matambalya, F. \& Wolf, S., The Role of ICT for the Performance of SMEs in East Africa: Empirical Evidence from Kenya and Tanzania, ZEF Discussion Papers on Development Policy, 2001.

[22] Murendo, C., Wollni, M., de Brauw, A. \& Mugabi, N., Social Network Effects on Mobile Money Adoption in Uganda. Global Food Discussion Papers, 2015.

[23] Mustonen-Ollila, E. \& Lyytinen, K., Why organizations adopt information system process innovations: a longitudinal study using Diffusion of Innovation theory. Information Systems Journal, 13(3), pp. 275-297, 2003.

[24] Murendo, C., Wollni, M., De Brauw, A. \& Mugabi, N., Social network effects on mobile money adoption in Uganda. The Journal of Development Studies, pp. 1-16, 2017. 
[25] Bartholomew, A., Udechukwu, O. \& Wainwright, D., Social networks among small agribusinesses in Nigeria. Society and Business Review, 6(3), pp. 214-228, 2011.

[26] Rogers, E.M., Diffusion of Innovations, Simon and Schuster, 2010.

[27] Mwombe, O.L.S., Mugivane, F., Adolwa, S.I. \& Nderitu, H.J., Evaluation of Information and Communication Technology Utilisation by smallholder Banana Farmers in Gataga District, Kenya. Journal of Agriculture Education and Extension, 20(2), pp. 247-261, 2014.

[28] Dearing, W.J., Applying Diffusion of Innovation Theory to Intervention Development, Research on social work practice, 2009.

[29] Valente, T.W. \& Rogers, E.M., The origins and development of the diffusion of innovations paradigm as an example of scientific growth. Science Communication, 16(3), pp. 242-273, 1995.

[30] Lee, Y.H., Hsieh, Y.C. \& Hsu, C.N., Adding innovation diffusion theory to the technology acceptance model: Supporting employees' intentions to use e-learning systems. Educational Technology \& Society, 14(4), pp. 124-137, 2011.

[31] Rogers, M.E., Diffusion of Innovations, New York: The Free Press, 1995.

[32] GSMA, Bridging the gender gap: Mobile access and usage in low and middle-income countries, London: GSMA Connected Women, 2015.

[33] Meinzen, R.D. et al., Engendering Agricultural Research, Development, and Extension, Washington: IFPRI Research Monographs, 2011.

[34] Gutsinda, SENTE Project VEA Mapping and Vetting Report, Kampala: Gutsinda Development Group, 2014.

[35] Hugh, W. \& White, H., Farmer field schools from agricultural extension to adult education, London: International Initiative for Impact Evaluation (3ie), 2014.

[36] Isubikalu, P., Stepping-stones to improve upon functioning of participatory agricultural extension programmes, Wageningen: Wageningen Academic Publishers, 2007.

[37] MAAIF, National Agricultural Extension Strategy 2016, Entebbe: Ministry of Agriculture Animal Industry and Fisheries (MAAIF), 2016.

[38] Semana, R.A., Agricultural extension services at crossroads: present dilemma and possible solutions for future in Uganda. at www.Codesriaorgan/links/conferenceslifs /semana pdf, 1999.

[39] Hakiza, J., Odongola, W., Mugisha, J. \& Semana, A.R., Challenges and prospects of disseminating technologies through farmer field schools: Lessons learnt based on experiences from Uganda. Uganda Journal of Agriculture Science, 9, pp. 163-175, 2004.

[40] Benin, S. et al., Returns to spending on agricultural extension: the case of the National Agricultural Advisory Services (NAADS) program of Uganda. Agricultural Economics, 42(2), pp. 249-267, 2011.

[41] Bahiigwa, G., Rigby, D. \& Woodhouse, P., Right target, wrong mechanism? Agricultural modernization and poverty reduction in Uganda. World Development, 33(3), pp. 481-496, 2005.

[42] Wairimu, W.W., Christoplos, I. \& Hilhorst, D., From crisis to development: the policy and practice of agricultural service provision in northern Uganda, 33(4), pp. 799-812, 2016.

[43] Musemakweri, J., Farmers' experiences and perceptions of the NAADS Agricultural Extension System/Program in Kabale district, Uganda: Iowa State University, 2007. 
[44] Tiraieyari, N., Khairuddin, I., Jegak, U. \& Azimi, H., Competencies influencing extension workers' job performance in relation to the good agricultural practices in Malaysia. American Journal of Applied Sciences, 7(10), pp. 1379-1386, 2010.

[45] Fangohoi, L., Sugiyanto Keppi, S. \& Edi Dwi, C., The role of cyber extension as media information of plantation genetic resources in the insurance of cocoa results in South Manokwari Regency West Papua. International Journal of Research Granthaalayah, 5(11), pp. 343-350, 2017.

[46] Cooper, W.A. \& Donna, L.G., Competencies needed to be successful county agents and county supervisors. Journal of Extension, 39(1), 2001. https://www.joe.org/ joe/2001 february/rb3.php.

[47] UBOS, National Population and Housing Census 2014: Main Report, Kampala: Uganda Bureau of Statistics (UBOS), 2016.

[48] MAAIF, National Agricultural Extension Policy 2016: Entebbe, Ministry of Agriculture Animal Industry and Fisheries (MAAIF), 2016. 